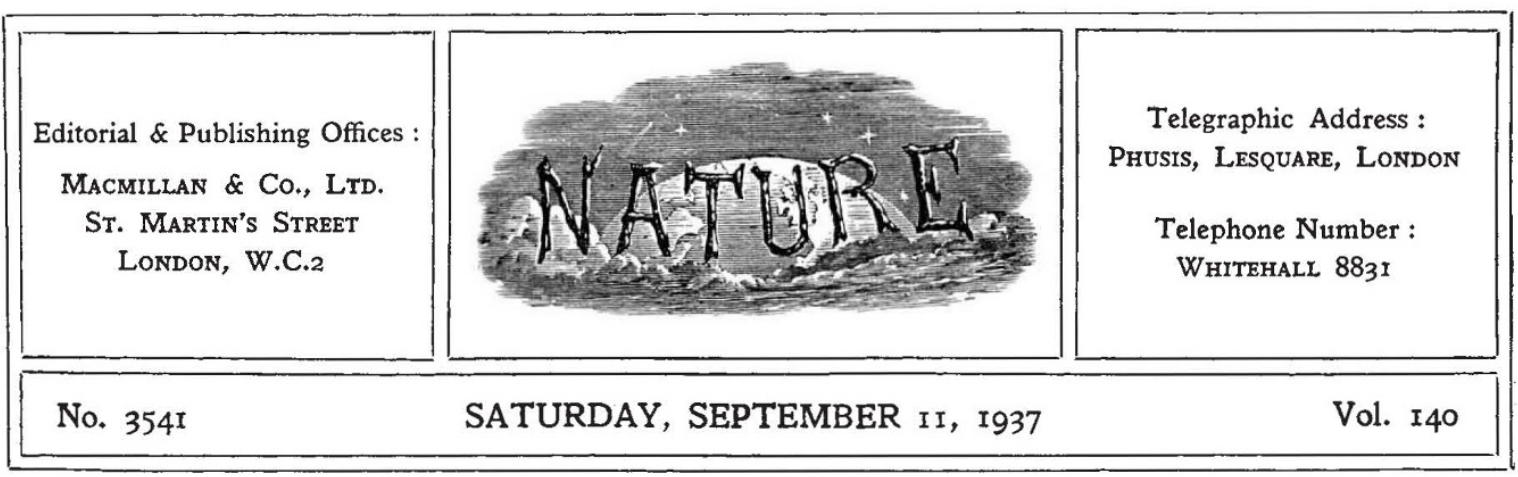

\title{
Research and Industry
}

IN his presidential address on September 2 to Section G (Engineering) of the British Association meeting at Nottingham, Sir Alexander Gibb took for his subject "Research and Engineering". $\mathrm{He}$ pointed out that engineering began as an art; at a later stage it developed into a somewhat scientific but purely empirical practice ; and that it is now at the final stage of applied science. The same transformations may be noted in many other industries, though it must be admitted that there is still a great number of industries yet in the second stage of development, and some even in the first. Nevertheless, there is an increasing attention paid in industry generally - and not only in engineering - to the vital necessity of continuous research as being, to quote the words of Sir Alexander, "the only means of continuous progress in an increasingly competitive world".

Sir Alexander Gibb gave a necessarily brief historical survey of the rise and development of research, which is a plant of very recent growth. Apparently he regards the beginnings of the national recognition of the value of research as dating back to less than a century ago, when the Royal Commission was appointed to find uses for a surplus of $£ 213,000$, made by the Great Exhibition of 1851. The money was used to purchase land in Kensington Gore, on which were built museums and schools of art, and also to provide science scholarships. Government grants from 1850 onwards to the Royal Society and private donations or bequests went to aid research in mathematics, physics, astronomy, biology, chemistry and general purposes.

In Great Britain, throughout this early period, original research continued to be mainly the work of individual scientific workers and was carried on chiefly at their own expense. Industry lagged far behind in its recognition of the value of scientific research, and it may be said, indeed, that it is only within very recent times that industry generally has accepted the view that scientific and industrial research is an essential factor in our industrial and national existence. It is also true to add that it needed the lessons of the Great War to open fully the eyes of the Government to the paramount need of systematic scientific research in our industrial organization.

Perhaps nothing in the development of the research movement is more significant than the way in which the distinction between pure and applied science, which was originally as sharp as the distinction between 'Gentlemen' and 'Players' at Lord's, has gradually lost its sharpness and become vague and indefinite. It is not so very long ago that, in many quarters, research into the internal structure of the atom was regarded as a noble and elevating pursuit of pure science, and research on soap as a rather ignoble, if not degrading, investigation-as though an atom were inherently dignified and became disreputable only when it was associated with other atoms to form the molecules of a homely, if necessary, commodity. Indeed, the artificial division between pure and applied science has dissolved perhaps most rapidly in the very laboratories which may seem, at first sight, to have been designed to buttress and perpetuate it. In industrial research laboratories, both at home and abroad, there is abundant testimony to the importance of 'pure science' research-what it is now the fashion to call 'fundamental research'. 
The same recognition is a remarkable feature of the experience of those industrial research associations which have been formed under the ægis of the Department of Scientific and Industrial Research. Almost with one voice they are crying out that the time and energies and the expenditure involved-necessarily and rightly involved-in solving ad hoc problems of great and immediate importance to the respective industries, leave them with too little time and energy and funds to be devoted to that fundamental research which they recognize as equally vital to the progress of industry. The solution, let it be said at once, demands not the curtailment of one to make possible the enlargement of the other, but adequate funds to enable both $a d$ hoc and fundamental research to be pursued on a sufficient scale.

We may note here that Sir Alexander Gibb says : "There is what one may call true fundamental research-splitting the atom, or extreme low temperature investigation." Perhaps it is convenient to call such research fundamental. It is a little difficult, however, to see how "splitting the atom" is more "fundamental" than splitting the molecule in ordinary industrial cracking processes; or to understand why "extreme low temperature investigation", more than high temperature researches in, say, polymerization or hydrogenation, is "true fundamental research". However, the point is one of small importance. In all cases of so-called industrial research, the ultimate need is nothing less than the full available knowledge of all the factors involved, and these factors include as well those that may conveniently be regarded as 'pure' or 'fundamental' as those of immediate industrial importance. The real aim of industrial research, whether in engineering or in any other industry, should be to elucidate the scientific principles involved, to gain the scientific knowledge needed and to apply the knowledge, in so far as it can be applied, to industrial practice. To achieve these aims it may be necessary to undertake what is called pure or fundamental research, on one hand, and applied research, on the other. But, at bottom, these constitute essentially one research purpose.

Another feature noticed by Sir Alexander in his address is the degree to which, in later years particularly, co-ordination and co-operation in research have become recognized as essential. Sir Alexander quotes the remarks of Mr. Thomas Midgley on the occasion of the award to the latter this year of the Perkin Medal of the Society of
Chemical Industry: "In any earlier age, when science and industry were simply individualistic processes, it is conceivable that some person, by his efforts alone, could have advanced applied chemistry to have justified your Committee to bestow upon him the Perkin Medal. To-day this is no longer so ; to advance applied chemistry, even a little, requires the organized efforts of many individuals." This is, of course, true also of industry and manufacture in general. The work undertaken by the various research boards of the Department of Scientific and Industrial Research, and the wide field of scientific and industrial research covered by the activities of the industrial Research Associations, all testify to the vital need to-day of co-ordination and co-operation in research. Scientific research is becoming less and less an individual effort and more and more a matter of team work.

Towards the conclusion of his address, Sir Alexander Gibb directed attention to the fact that, the greater the success of research, the more immediate and drastic is the effect on existing plant and equipment. He says: "Millions are necessarily sunk in fixed assets, which may in a year or two be made obsolete by the development of new methods", and he declares that many valuable inventions have been bought up by vested interests and suppressed, in order to save the greater loss that their exploitation would involve to already operating plant. This particular allegation has been made so often that it is difficult to believe there is not a good deal of truth in it. The lack of data of specific instances of inventions being purchased only to be promptly strangled is, however, a great handicap to any assessment of what the nation has lost and may lose by such a practice. Not many years ago, large commercial combinations were regarded with deep suspicion, as being nothing but price rings. But the findings of a Government inquiry into the extension of trade organizations and combinations did a great deal to allay public mistrust. The question arises whether a similar Government inquiry should be made into this alleged practice of smothering valuable inventions at, or soon after, their birth. It might turn out that the practice neither goes so deep nor is so widespread as popular impression allows. On the other hand, if such an inquiry should reveal a grave public mischief, appropriate measures could be taken. From every point of view, however, it is desirable that precise information should be available on this subject. 